\title{
An Empirical Examination of the Impacts from Termination of a Performance-Based Incentive
}

\section{Plan}

\author{
Rajiv D. Banker \\ Temple University \\ Seok-Young Lee \\ Sungshin Women's University, South Korea \\ Gordon Potter \\ Cornell University \\ Dhinu Srinivasan* \\ University of Pittsburgh
}

We gratefully acknowledge helpful comments from Jake Birnberg, Harry Evans, Joan Luft, Reed Smith, R. Venkatesh, and seminar participants at Georgetown University, Indian School of Business, Purdue University, Rutgers University, Syracuse University, Tilburg University, and The University of Texas at Dallas.

* Corresponding author. Address: 266 Mervis Hall, Katz Business School, University of Pittsburgh, Pittsburgh, PA 15260. Phone: 412-648-1513. Fax: 412-648-1693. Email: dhinus@katz.pitt.edu 


\title{
An Empirical Examination of the Impacts from Termination of a Performance-Based Incentive \\ Plan
}

\begin{abstract}
This paper reports on the financial impacts from the termination of a pay for performance plan for the salesforce at a retail establishment. Using monthly panel data spanning more than eight years for 15 outlets of a major retailer, this study documents that store-level sales and operating profits decrease after the incentive plan is terminated. Individual performance data are then investigated to help identify the role of effort and selection effects in explaining the documented decrease. The analysis of the individual employee sales data reveals that virtually all of the declining store level sales can be explained by selection effects.
\end{abstract}

Key words: Incentive compensation; pay for performance; agency theory; termination of incentive plan; sales force compensation 


\section{An Empirical Examination of the Impacts from Termination of a Performance-Based Incentive}

\section{Plan}

\section{Introduction}

In spite of a large body of academic literature arguing against the power of incentives to enhance performance, there is growing evidence that performance-based compensation contracts for front-line employees leads to improved financial performance [Prendergast 1999, Rynes et al. 2005). At the same time, the use of incentive pay by firms to reward workers for their productivity has been increasing (Bidwell et al. 2013, Aon Hewitt 2014). Despite the perceived success of these incentive plans and the recent evidence of their growth, many firms have curtailed or terminated their incentive plans. ${ }^{1}$ This study reports on the financial impacts that arise from termination of an incentive plan for front-line salesforce employees at a large retail firm. We find that the performance impacts upon plan termination are consistent with the predictions of economic theories of incentives.

Over the past two decades considerable theoretical research in accounting, economics and marketing has investigated the optimal structure of compensation contracts. In the basic agency model, a principal designs incentive contracts to induce risk-and effort-adverse agents to exert higher levels of effort and to sort these agents based on their ability. Empirical studies by Lazear (2000), Paarsch and Shearer (2000), Oettinger (2001), and Banker et al. (2000), among others, document effort and/or selection impacts from the implementation of performance based incentives across an array of industries. In marketing, effort and selection effects of incentive contracts have been examined by Lo et al. (2011) and the impact of the form of the incentive contract and its payout frequency on performance by Misra

\footnotetext{
${ }^{1} \mathrm{Chu}$ (2004) reports on a study by Hewitt Associates that found that about $83 \%$ of companies with pay-for-performance plans claim the plans are not working at all, or are only somewhat successful. Reasons provided in the study for the poor results include funding issues, inability of firms to measure the effectiveness of these pay strategies, and difficulties learning how to effectively implement these plans. Beer and Cannon (2004) report on the elimination of thirteen incentive plans at HewlettPackard. Firms such as Dupont (Humphrey 1990a, b), Schering-Plough (Laabs 1997) and Fujitsu (Tanikawa 2001) have attenuated their incentive plans. Glaxo SmithKline unveiled an initiative in 2010 stating that the company would no longer link bonuses to sales targets and instead reward sales staff for their scientific knowledge (Torsoli and Staley, 2014). Chi, Freeman and Kleiner (2011) report on the elimination of numerous employee involvement programs in the manufacturing industry. The Chinese Academy of Sciences (CAS) recently has reduced the reliance of their scientists' salaries on competitive grants to $30 \%$ from 70\% (Cyranoski, 2014). These changes are in spite of Rigby's (2001) survey data revealing that firms are more satisfied with incentive pay than any other management practice.
} 
and Nair (2011), Kishore et al. (2013), and Chung et al. (2013). Thus, evidence is accumulating that performance-based compensations can have both effort and selection effects. Less is known about the relative magnitudes of the two effects, or when one of them may or may not be present.

The economic theories and empirical evidence supporting the benefits of incentive compensation suggest that the termination of a rewards-based incentive plan would result in lower firm performance due to reduced effort by employees and selection problems as high performers leave the firm and are replaced by employees of lower ability. Arguments from organization theory and cognitive psychology present a contrary viewpoint. In a meta-analysis of over one hundred experimental studies, Deci et al. (1999) conclude that in most instances rewards have a negative effect on intrinsic motivation. ${ }^{2}$ Thus, the removal of monetary incentives may increase an employee's engagement and her performance. In addition, in many stores in our study, the incentive plan was in place for over two years. Workers with multi-period decision horizons that are provided incentives devote effort to learn more productive ways to perform their tasks (Latham and Dossett 1978, Wagner, et al. 1988, Sprinkle 2000). Therefore, the incentive plan may have resulted in gains in human capital of employees that have lasting returns resulting in attenuated impact on performance upon termination of incentives (Gneezy et al. 2011).

Implementation of incentive plans is also usually accompanied by changes in other human resource policies such as recruiting and training, and additional attention from managers resulting in potential Hawthorne effects. The documented selection effects in previous implementation studies of incentive plans might be attenuated because attracting individuals of high ability might require additional human resources by the firm. Thus, an analysis of the termination of incentives may provide a better setting to examine and quantify effort and selection effects. Finally, limited empirical evidence on the termination of incentives finds little performance deterioration. While Jaques et al. (1951) find inconclusive results upon plan termination, Rothe (1970) documents that, although there is an immediate

\footnotetext{
2 Kohn (1993) and Pfeffer (1998) state that incentive compensation results in a lack of cooperation, absorbs a vast amount of management time, and ultimately, results in dissatisfaction and lower performance. Thus, when performing a task that subjects find intrinsically interesting, the introduction of monetary incentives decreases subsequent interest and performance. Some recent economic literature addresses the "hidden cost of incentives". Focusing agents on extrinsic rewards may "crowd out" any intrinsic motivation the agent has to complete the task (see Kreps 1997, Benabou and Tirole 2003, Frey and Oberholzer-Gee 1997 and Gneezy and Rustichini 2001, among others).
} 
decline in productivity upon the termination of an incentive plan, six months after termination productivity exceeds that realized during the incentive plan period.

This paper examines the long-term financial impacts resulting from the termination of an incentive plan. The implementation of the incentive plan in this study is described in Banker et al. (1996). The plan was selectively implemented in approximately half of the retail stores of a major retail chain and terminated about three years later. Termination impacts are examined over a two-year period subsequent to the plan's termination. The setting is particularly suitable for examining the termination of explicitly calibrated incentives. The company had implemented the incentive plan in only 15 of its 34 retail outlets that it operates over a relatively homogeneous geographic region, providing a natural control group of 19 stores. Moreover, upon termination there was no change in information detailing individual performance, thus any influence of an individual's reported productivity on behavior was maintained. In addition, many individuals' hourly wage at the termination date was increased to reflect prior productivity, and future wage increases were implicitly tied to future productivity.

Given these conditions, to the extent the post termination wage levels are above the workers' going rate and there is a credible threat of being fired, efficiency wage theory suggests that even after the plan's termination employees may continue to have an incentive to exert high effort or to remain with the firm in order to maintain their employment (Salop 1979, Shapiro and Stiglitz 1984, Yellen 1984). Nevertheless, we find that the termination of the plan is associated with a drop in both sales and operating profits relative to those levels prior to the plan's termination. By examining individual productivity changes around the plan's termination we document that virtually the entire sales decline is explained by a workforce selection effect. Specifically, we document that the permanent employees who join the firm after the plan's termination are less productive than those who leave during the same period. Thus, our research indicates that perhaps explicit incentives' largest impact is in determining the composition of the workforce, rather than in motivating effort. 
The paper is structured as follows. Section 2 provides a review of extant research on impact of incentive plans. Section 3 describes the research site and outlines the testable hypothesis. Empirical methods and results are discussed in Section 4. Concluding remarks are offered in Section 5.

\section{Literature review}

Agency theory is one paradigm that suggests a value for performance-based compensation. Examples of agency-theoretic models for examining salesforce compensation include Basu, Lal, Srinivasan, and Staelin (1985), Lal and Staelin (1986), Rao (1990), and Hauser et al (1994). In the basic agency model, a principal designs a contract to motivate a risk-and effort-adverse agent to exert unobservable effort in a production process that is characterized by uncertainty. Given the compensation contract, the agent is induced to trade-off her disutility for effort against her expected utility for higher compensation resulting from improved performance and risk bearing. Performance-based incentives also have the effect of revealing the unknown intrinsic ability of employees to the firm (Murphy, 1986). If the more productive employees have the better outside opportunities, implementation of a pay-forperformance system amounts to offering a menu because it allows employees to determine their compensation by how hard they choose to work. Indeed, paying a wage that is based on measured performance tends to attract and retain the most productive job applicants and to discourage the least productive, to the employer's benefit (Milgrom and Roberts 1992, Balmaceda 2008) resulting in a beneficial sorting effect. Thus, pay-for-performance attracts workers of higher ability and induces workers to provide higher effort (Booth and Frank 1999, Prendergast 1999, Lo et al. 2011).

Empirical evidence documents impacts consistent with the predictions of agency theory. Studies by Abowd (1990), Brooks et al. (2001) and Morgan and Poulsen (2001) find that the adoption of pay for performance plans for top executives results in increased performance. Research concerning front-line employees also documents productivity gains from incentive compensation consistent with effort effects. Banker et al. (1996) find an immediate increase in sales upon the adoption of bonus program for sales consultants. Lazear (2000) documents a rise in worker productivity upon the adoption of a piece-rate system for line employees at an installation facility. Paarsch and Shearer (2000) estimate higher 
productivity for piece workers at a tree-planting firm. Oettinger (2001) finds that higher commission piece rates for vendors leads to improved performance. Examples of empirical studies in marketing that examine agency-theoretic predictions of salesforce compensation include Coughlan and Narasimhan (1992), John and Weitz (1989) and Coughlan et al. (2005). Chung et al. (2013) document positive incentive impacts for the salesforce at an office products firm. They also, along with recent work by Kishore et al. (2013) and Misra and Nair (2011), examine impacts of the specific form the incentive contract. Joseph and Kalwani (1995) document that incentive compensation increases with a sales associate's tolerance for risk, also supporting the agency framework. With respect to compensation premiums, Ewing (1996) and Booth and Frank (1999) find that employees on incentive pay earn more than those who have fixed pay, reflecting the risk sharing and effort inducing effects of incentive compensation in the agency model.

The evidence on pure selection impacts of incentive contracts is more limited (Mantrala et al. 2010). In a laboratory setting, Cadsby et al. (2007) document that the effort effect of performance-based contracts was less important in explaining performance than the sorting effect. Using a survey of sales managers, Lo et al. (2011) document that sales agents with greater selling ability are associated with more high-powered incentives. Lazear (2000) finds that performance pay results in the hiring of higher ability workers. Banker et al. (2000) document that incentive pay results in the attracting of workers who are more productive than those that leave. Thus, evidence is accumulating on the usefulness of performancebased incentives to act as a selection device.

Despite this evidence, the ability of agency theory to explain firms' use of performance-based incentive systems is not strong (Stewart 1999, Baker 2000). Jensen and Murphy (1990) find compensation of chief executive officers is not very sensitive to shareholder wealth changes. In part this is due to the fact that firms reduce the sensitivity of pay to performance to shelter the agent from risk (Baker 2000). Incentives may also lead to a gaming of the system. Holmstrom and Milgrom's (1991) two-dimensional effort model indicates that when the outcome of one of the effort dimensions cannot be measured at all, dysfunctional behavior can occur. This undesired behavior results in principals 
weakening the link between incentives and performance measures. Moreover, Lazear's (1989) tournament model suggests that when workers can impair their co-workers' efforts, firms reduce incentives. An example of this destructive behavior is provided by Drago and Garvey (1998). They document that when promotion incentives are strong, workers are less likely to let their colleagues share their equipment.

Efficiency wage theory suggests that paying above market fixed wages may resolve the effort and selection problems addressed above (Yellen 1984). For instance, Shapiro and Stiglitz (1984) develop a model where paying a wage above market creates unemployment but provides workers with an incentive to not shirk, as they may get caught and face unemployment. Cappelli and Chauvin (1991) find support for this theoretical model by documenting a negative association between relative wages and discipline rates across plants. Salop (1979) develops a model in which firms, desiring to reduce turnover costs, pay workers above market rates. In this model workers may be more reluctant to quit when the wage they are paid is high. Campbell (1993) documents empirical evidence consistent with this argument. Thus efficiency wages may be another mechanism to resolve effort and selection problems. In Rothe's (1970) study of welders, explicit incentives were replaced with a new contract that included an increase in fixed wages. Therefore, the gain in output after incentive removal documented by Rothe may be explained by efficiency wage theory. At our research site, because the termination of the pay-for-performance plan resulted in an average increase in wage rates and continued monitoring of productivity, efficiency theory suggests overall productivity may not change upon the plan's termination.

\section{Research Site and Hypotheses}

\section{Description of Site and Plan}

Our research site consists of 34 retail outlets of a large Fortune 500 full-line department store that operates over a relatively homogeneous geographic area. This company had sequentially implemented an incentive plan for frontline "sales consultants" in 15 of its 34 stores. Sequential implementation occurred because the plan required corporate resources and the company was uncertain how the new plan would 
impact store performance. Sequential and partial implementation provides us with a natural control group for our study.

Prior to adopting the plan, straight salary had been provided to the salesforce. Salary increments had been based primarily on seniority, not performance. The pay-for-performance plan kept an employee's base salary intact. Upon implementation, in addition to keeping their base salary, the employees were paid a bonus if their actual sales exceeded their individual sales target. Therefore, the incentive plan is best described as a commission at quota plan (Kishore et al. 2013, Chung et al. 2013). Each salesforce consultant was given a sales goal determined in part on hourly wage rate and general merchandise class. Implementation of the incentive plan coincided with a change in the information system and employee decision rights. Upon implementation, each member of the salesforce was provided with an individualized report on sales productivity. In addition, employees were trained in customer service and provided more authority to close a sale.

\section{Termination of Plan}

About 34 months after the plan was implemented announced that it was terminating the plan in the 15 stores as of the end of the quarter. This change coincided with a change in top management at the firm and strategic positioning of the retail chain. Beginning in the fiscal quarter after termination, sales consultants were to receive their pay determined by their base wage rate or, a new higher hourly wage rate that approximated their actual pay over the prior four quarters. Thus many employees received an hourly rate pay raise upon the plan's termination. Future annual pay increases were to be based, in part, on actual individual productivity after the plan's termination. Individual productivity continued to be measured and reported at the end of each quarter subsequent to the plan's termination.

\section{Hypotheses Development:}

\section{Immediate Impact of Plan's Termination}

Retail sales consultants need to expend considerable effort to provide customer service and to close sales. Higher effort by the sales force includes being present on the sales floor, approaching customers, assessing the needs of customers, and working to satisfy those needs. Monetary incentives 
linking pay to performance motivate sales consultants to provide better customer service (Schwadel, 1990). At our research site, performance-based pay had been used for the sales force prior to plan's termination. Therefore, the termination of the performance-based incentive contract will reduce the sales consultants' desire to exert effort.

\section{$H_{1}$ : Performance decreases immediately following the termination of the performance-} based compensation plan.

While the above hypothesis follows from the basic agency model of incentives, as discussed earlier, to the extent the post termination wage levels are above the workers' going rate and there is a credible threat of being fired, efficiency wage theory suggests that employees may continue to have an incentive to exert higher than the minimal effort in order to maintain their current employment. Moreover, to the extent that sales supervisors and managers provide (imperfect) monitoring and feedback of sales consultants' effort, consultants continue to be motivated to direct their effort in the desired direction. These factors argue against any negative impacts from the plan's termination.

Predictions from the cognitive psychology literature are also not clear cut. Deci and Ryan (1985), and Lepper et al. (1973), among others, report that in performing tasks that subjects find intrinsically interesting, introduction of monetary incentives decreases subsequent interest and performance. Camerer and Hogarth (1999) also conjectured that incentives may hurt in difficult judgment or decision tasks or when they make people self-conscious about an otherwise straightforward activity. However, after reviewing a number of experiments that include financial incentives they conclude that, although in general incentives do not impact performance, incentives seem to "improve performance in easy tasks that are effort-responsive." They include in this category clerical tasks "which are so mundane that monetary reward induces persistent diligence when intrinsic motivation wanes."

\section{Continuing Impacts of Plan's Termination}

Performance-based compensation may lead to positive benefits from repeat purchases by satisfied customers, learning by consultants and selection effects. Once an explicit opportunity to realize higher pay is removed, sales consultants may see little reason to expend effort on activities that satisfy 
customers' needs. Once customers realize that service has deteriorated, they may be less likely to return to the store resulting in a slow erosion of sales.

The removal of incentives may also discourage employees from learning improved ways to perform tasks. Workers with multi-period decision horizons that are provided incentives devote effort to learn more productive ways to perform their tasks (Latham and Dossett 1978). Learning effects result as workers become more familiar with their responsibilities, adopt more productive procedures and eliminate unproductive activities (Wagner et al. 1988). In a laboratory experiment, Sprinkle (2000) documents strong positive performance effects from incentives over time as agents learn about the nature of the task based on feedback. In our setting, feedback information on individual performance was continued, but not explicit incentives. Once these incentives were removed, consultants might have lost their desire to focus effort on learning or on generating repeat sales.

Performance may also decrease over time as productive employees, unhappy with the new flat wage program, leave and are replaced by personnel with lower intrinsic ability (Rao, 1990). Economic theory suggests that in adverse selection situations involving a pool of workers with different levels of intrinsic ability, contracts that are contingent on performance induce a separating equilibrium with the higher-ability workers optimally accepting the contingent contract and the lower-ability workers rejecting it. Lazear (2000) finds that performance pay results in the hiring of higher ability workers. Banker et al. (2000) document that incentive pay results in the attracting of workers who are more productive than those that leave. Lo et al. (2011) find that sales agents with greater selling ability are associated with high-powered incentives. Thus, over time the new flat wage contract may attract more low-ability workers and retain such workers already in its employment, but lose high-ability workers in its employment subsequent to termination. Thus, a continuing decrease in performance is predicted.

\section{$\mathrm{H}_{2}$ : Performance will continue to decrease following the termination of the incentive plan.}

One economic argument against this prediction includes possible consequences of the multitasking problem (Holmstrom and Milgrom 1991, Feltham and Xie 1994, Baker 2000). If monetary 
incentives are based on a performance measure (e.g., current sales) that results in a reduction of other important effort dimensions, then dysfunctional behavior may have ensued under the pay for performance plan with excessive effort being directed to the effort dimension being rewarded by performance-based incentives. For instance, Paarsch and Shearer (2000) noted at their research site that, although piece-rates resulted in productivity increases, reject rates increased. In a multi-period situation such as the one we encounter at our research site, the ability of consultants to increase sales without providing better customer service may be limited. However, at our site the accounting for sales returns was a source of contention under the incentive plan as the dollar value of the returned merchandise was counted against the actual sales of the consultant receiving the returned merchandise, not the consultant that sold the goods. If consultants were allocating too much effort to closing current sales at the expense of building strong customer bases and of learning effective sales methods, performance may improve subsequent to the plan's termination.

Efficiency wage theory also argues against subsequent large drops in performance through its effect on selection and effort. Upon the plan's termination an individual's hourly wages are pegged to her implied productivity. This may mitigate the willingness of high ability workers to leave as they are now paid for their ability. Moreover, because individual sales continue to be monitored, if workers believe there is a chance of being terminated for low performance, positive long term effort and sorting effects may result after termination.

\section{Results}

\section{Preliminaries}

Estimates of the impacts of the plan's termination are based on relative store performance by comparing the 15 stores that adopted and then terminated the plan versus the 19 stores in the region that never adopted the plan. Table 1 presents average statistics on store sales, operating profits and square footage by existence of the incentive plan for the fiscal year immediately preceding termination. Because of the sensitivity of the information, the data have been disguised by multiplying by a scalar. The median square feet for the 15 plan and the 19 non-plan stores are identical, and the difference in the means is not 
statistically significant. There are also no statistically significant differences in store size as measured by total sales. Sales and operating profits per square foot are somewhat higher for the stores that have been on the incentive plan. This finding is consistent with the incentive plan resulting in improved financial performance.

Table 2 presents a comparison of key financial ratios for the plan and non-plan stores for the same period. There are no statistically significant differences in cost of sales/sales ratios. Selling expenses, which represent the salaries and wages of frontline employees and their managers, relative to sales are significantly higher in the plan stores. These results are consistent with performance-based pay resulting in higher labor costs. The support expenses/sales ratio is greater on average for the non-plan stores, reflecting perhaps a fixed cost effect driven by more throughput at the stores on the plan.

While not reported in a table, we examined a sample of the hourly wage rates for employees on the incentive plan immediately prior to and after termination of the plan. We estimate that base hourly wages, after controlling for inflation, increased by $16 \%$ from the last quarter on the plan to the first quarter subsequent to termination. This confirms management's intent to increase fixed wages upon the plan's termination, and argues against any dramatic drops in performance from the plan's termination.

\section{Model Specification}

Empirical testing of the hypotheses derived in the previous section involves assessing the impact of the termination of the incentive plan on store performance. We obtained monthly store financial results for a 99-month period for the 15 stores that implemented the incentive plan and the 19 other stores in the same geographic region that did not. To estimate the plan's effect on sales we specify the following model of sales in month $t, t=1, \ldots, 99$, of each store $s, s=1, \ldots, 15$, that implemented the plan:

$$
\begin{gathered}
\text { SALES }_{s t}=\sum_{s=1}^{15}\left(\alpha_{s} \mathrm{D}_{s}+\beta_{s} \mathrm{D}_{s} \operatorname{AVGSAL}_{t}\right)+\sum_{q=2}^{4} \eta_{q} D_{q}+\gamma \mathrm{RGINC}_{\mathrm{st}} \\
+\lambda_{1} \mathrm{D}_{s t}^{P}+\lambda_{2} \mathrm{PLANEXP}_{s t}+\lambda_{3} \mathrm{D}_{\mathrm{st}}^{\mathrm{T}}+\lambda_{4} \mathrm{TERMEXP}_{s t}+e_{s t}
\end{gathered}
$$

where, 
SALES $_{s t}=$ sales per thousand square feet of store $s$ in month $t$,

$\operatorname{AVGSAL}_{t}=$ average sales per thousand square feet in month $t$ of 19 'control' stores that did not implement the incentive plan,

RGINC $_{s t} \quad=$ relative growth in personal income of county of store location.

$\mathrm{D}_{q} \quad=1$ if quarter $\mathrm{q}$, otherwise zero.

$\mathrm{D}_{s} \quad=1$ if store $\mathrm{s}$, otherwise zero.

$\mathrm{D}_{s t}^{P} \quad=1$ in the months after implementation of the incentive plan, otherwise 0.

$\operatorname{PLANEXP}_{s t} \quad=$ Number of months since implementation of the incentive plan.

$\mathrm{D}_{\mathrm{st}}^{\mathrm{T}} \quad=1$ in the months after termination of the plan, otherwise zero.

TERMEXP $_{s t}=$ Number of months since termination of the plan.

In this formulation store sales are specified as an intercept $\alpha_{s}$ plus a multiple $\left(\beta_{s}\right)$ of $A V G S A L_{t}$.

The $\beta$ parameters vary across stores principally due to relative sensitivity of sales to region-wide sales for the company. We compute the $A V G S A L_{t}$ measure for each month $t$ using the 19 stores that did not implement the plan and thus, control for changes in sales over time because of the potentially unique selling strategies of the firm as well as seasonal and economy-wide effects. Monthly performance of the 34 stores moves together over time due to overall retailing patterns as well as firm specific reporting periods, sales promotions, and advertising strategies. We estimate the model's parameters using pooled time-series data over a 99 month period and cross-sectionally for the 15 stores that implemented the incentive plan. Estimation of the termination impacts on Operating Profit (PROFIT) is conducted in a similar manner.

During our analysis we determined that the average growth rate in county personal income for the plan stores is significantly greater than that for the non-plan stores in the period immediately preceding termination. Because more disposable income is believed to translate into more sales, sales changes may 
be driven by differential personal income growth rates. To control for the impact of income growth on store performance we include the variable, $\mathrm{RGINC}_{\mathrm{st}}$.

We test for the hypothesized effects of the implementation and termination of the incentive plan on sales by examining the intercept shift coefficients, $\lambda_{1}$ and $\lambda_{3}$, and slope shift coefficients, $\lambda_{2}$ and $\lambda_{4}$, in the model. A positive $\lambda_{1}$ (negative $\lambda_{3}$ ) is interpreted as adoption (termination) of the incentive plan having an immediate positive (negative) effect on sales. Estimates of $\lambda_{2}\left(\lambda_{4}\right)$ examine continuing improvements (declines) from the adoption (termination) of the plan. Overall termination impacts are measured with $\mathrm{F}$ tests on combinations of the parameter estimates.

We control for serial correlation in our time-series data by using a variant of the Prais-Winsten (1954) estimator proposed by Park and Mitchell (1980). We do not expect to find heteroscedasticity, as dividing each financial variable by number of square feet controls for differences in store size. We also present an alternative estimation model later in the paper to verify the robustness of our results to model specifications.

\section{Estimation Results}

Figure 1 presents a plot of the average standardized sales residuals for the 15 stores that implemented and then terminated the incentive plan. The residuals are centered in the month of the plan's termination. The residuals for each of the 15 stores are computed as prediction errors from the following model:

$$
\operatorname{SALES}_{\mathrm{st}}=\alpha_{\mathrm{s}}+\beta_{\mathrm{s}} \mathrm{AVGSAL}_{\mathrm{t}}+\varepsilon_{\mathrm{s}}
$$

The parameters, $\alpha_{\mathrm{s}}$ and $\beta_{\mathrm{s}}$, are estimated using all of the monthly sales data prior to the plan's termination. The residuals are standardized by scaling by the square root of the out-of-sample prediction error variances. The figure reveals a continuing drop in unexpected sales beginning around the time of the plan's termination.

Our estimates of termination impacts are presented in Table 3. The parameter estimates for the impact on sales per thousand square feet are presented in the third column. The coefficients confirm that 
the adoption of the plan resulted in an immediate $\$ 685.18$ increase in sales per thousand square feet relative to the control group. Moreover, sales gains increased $\$ 88.96$ per month thereafter. More pertinent is the immediate drop in sales performance upon the plan's termination. Examination of $\lambda_{3}$ reveals a drop in sales of $\$ 990.13$ in the month immediately following the plan's termination. The coefficient on TERMEXP indicates that sales decreases accelerate over time after the plans termination. Overall, the results suggest that eliminating the incentive plan results in a decrease in sales that is consistent with Hypotheses 1 and 2.

Linear contrasts presented at the bottom of the table reveal that while the incentive plan's termination resulted in dampening sales, the sales erosion does not result in erasing all of the gains from the plan. For instance, at the time of termination, a store on average had been on the plan for 34 months. A test of the contrast $\lambda_{1}+34 * \lambda_{2}+\lambda_{3}=0$ reveals that sales remain above pre-plan levels. As revealed in the bottom contrast, overall sales gains attributable to the plan persist 24 months after the plan's termination. Therefore, while the plan's termination resulted in a drop in sales relative to levels evidenced under the plan, 24 months after termination not all of the gains attributable to the plan had been erased.

The far right column estimates the impacts of implementing and terminating the plan on operating profit. Note that the plan's implementation did not result in an immediate increase in profits. Rather, operating profits declined a significant $\$ 185.71$. This is consistent with compensation increases resulting from the plan's bonus payment system. Parameter estimates of the plan's immediate impact upon termination indicate profits dropped relative to pre-termination levels. Profit erosion continues subsequent to termination at a rate of $\$ 30.72$ per month. However, as evidenced by the contrasts at the bottom of the table, post-termination profits remain above pre-plan levels.

Table 4 presents estimates of impacts using a relative performance model. This model is constructed by scaling a store's performance per square feet by similar performance of the control stores. For instance, estimation results suggest that relative sales increased $7.1 \%$ immediately upon the plan's 
implementation and continued to increase about $0.5 \%$ per month thereafter. Plan termination resulted in an immediate $5.3 \%$ decrease in relative sales and that sales eroded at a rate of $0.7 \%$ per month thereafter. An examination of the contrasts reveals that, as estimated in the prior model, although relative sales declined after the plan's termination not all of the sales gains had been erased. However, the profit results in the right column indicate any profit gains attributed to the plan had dissipated. We also estimated regression models with only intercepts or slopes for different time-periods (years) following plan implementation and termination. The results (not shown) are consistent with those of Tables 3 and 4 . In summary, the results using these alternative estimation models confirm the primary results presented in Table 3.

Overall the results suggest that the termination of the incentive plan resulted in immediate and continuing decreases in sales and operating profits. These results are consistent with the termination of pay for performance resulting in agents trading off the expectation of lower wages with lower effort given imperfect monitoring. There is no evidence that terminating the plan resulted in improved performance, contrary to some organizational theories and the work of Rothe (1970). There is evidence that most, but not all, of the gains attributable to the incentive plan had eroded in the 24 months after the plan's termination. However, given the length of time-series data after termination, it is not possible to determine whether the net performance gains attributable to the incentive plan would have remained over longer periods.

\section{Impact of Termination on Individual Performance}

Our results thus far have focused on performance consequences of termination of the incentive plan at the store level. As discussed earlier, performance consequences may be a result of either an effort effect, i.e. the change in an employee's productivity over time due to changes in effort level as a result of (or lack of) incentives, or a selection effect that occurs because employees with varying abilities are attracted to different firms based on the type of employment contracts. To help ascertain which of the effects may explain the results presented above we analyze 37,623 observations of employee specific 
quarterly sales productivity for 5,802 employees from the 15 retail outlets over a ten quarter period. ${ }^{3}$ In addition to individual's actual quarterly sales, individual employee information includes hours worked in a quarter, store, merchandise group, and the number of years of service at the store by an employee.

To examine the selection and effort effects caused by the plan's termination, we classify each employee in our sample into one of the following four types: employees who join the store after incentive plan termination and who remain until the end of our sample period (JOINSTAY - JS), employees who join the store after incentive plan termination and who leave the store prior to the end of our sample period (JOINQUIT - JQ), employees who are with the store before plan termination and who leave prior to the end of our sample period (EXISTQUIT - EQ), and those who are with the store before plan termination and who remain until the end of our sample period (EXISTSTAY - ES). To evaluate the effort effect of the termination of plan over time, we construct a variable TERMQTR that measures the number of quarters an employee works after termination of the plan. The variable TERMQTR takes on the value one in the employee's first quarter after termination and increases by one for each quarter completed thereafter. We also include a variable PLANQTR that captures the change in sales productivity of existing employees' during two quarters in the plan immediately before termination. Also included is a variable STOREQTR that measures the number of quarters of an existing (i.e. EXISTQUIT and EXISTSTAY) employee's experience at the store prior to plan termination.

We measure an employee's productivity as her average sales per hour (expressed in constant dollars after deflating by CPI) in a quarter (HSALES). While our model controls for inflation by deflating sales dollars using CPI, time-series data may be sensitive to temporal changes in retail sales productivity due to other economy-wide, industry- and firm-specific events. Therefore, we estimated our model by including a control (CNTRLSPH) measured as the average quarterly sales per hour for the 19 control stores that did not implement the incentive plan. Because hourly sales productivity may vary by store due to demographic, competitive environment or management styles, we include an indicator

\footnotetext{
3 The individual data period starts two quarters before, and ends eight quarters after, termination of the plan. The
} firm did not collect individual performance information for employees at non-plan stores during the sample period. 
variable (denoted by the subscript s) for each store. In addition, we include indicator variables for the 14 merchandise groups (denoted by the subscript w) such as children's, men's and women's wear, and accessories, because these categories within a store may require varying degrees of employee effort and store support in the form of advertising and promotional sales. Finally, because the selling season has a large impact on sales productivity, we also include indicator variables for the fiscal quarter (denoted by q).

We estimate sales productivity by the following model.

$$
\begin{aligned}
& \text { HSALES }_{i t}=\alpha+\sum_{S=2}^{15} \beta_{S} D_{S}+\sum_{w=2}^{14} r_{w} D_{w}+\sum_{q=2}^{4} p_{q} D_{q}+\gamma \text { CNTRLSPH }_{t}+\mu \text { PLANQTR }_{i t}+\eta \text { STOREQTR }_{i} \\
& +\lambda^{E S} D^{E S}+\lambda^{J S} D^{J S}+\lambda^{E Q} D^{E Q}+\lambda^{J Q} D^{J Q}+\delta^{E S} D^{E S} \text { TERMQTR }_{i t}+\delta^{N S} D^{N S} \text { TERMQTR }_{i t} \\
& +\delta^{E Q_{D}} Q_{\text {TERMQTR }}+\delta^{N Q_{D}}{ }^{N Q_{T E R M Q T R}}+\varepsilon_{i t}
\end{aligned}
$$

where

$\mathrm{i} \quad=1 \ldots 5802$, denotes employee $\mathrm{i}$,

$\mathrm{t} \quad=1 \ldots 10$, denotes the time-period in which the employee works,

HSALES $_{\text {it }}=$ employee i's sales per hour (in constant dollars) in time-period t,

$\mathrm{D}_{\mathrm{si}}=\mathrm{a}$ dummy variable to represent the store $\mathrm{s}$ in which the employee works,

$=1$ if employee $\mathrm{i}$ works in store $\mathrm{s}(=1 \ldots 15),=0$ otherwise,

$\mathrm{D}_{\mathrm{wi}} \quad=$ a dummy variable to represent the merchandise group $\mathrm{w}$ in which the employee works,

$=1$ if employee $\mathrm{i}$ works in merchandise group $\mathrm{w}(=1 \ldots 14),=0$ otherwise,

$\mathrm{D}_{\mathrm{qt}}=$ a dummy variable to represent the fiscal quarter $\mathrm{q}(=1 \ldots 4)$,

$=1$ if the time period $\mathrm{t}$ is the same as fiscal quarter $\mathrm{q},=0$ otherwise,

$\mathrm{D}_{\mathrm{i}}^{\mathrm{ES}} \quad=$ a dummy variable that represents an EXISTSTAY employee,

$=1$ if employee $\mathrm{i}$ is EXISTSTAY,$=0$ otherwise,

TERMQTR = Number of quarters of service by an employee after termination of the plan, 
CNTRLSPH = Average quarterly sales per hour for the 19 control stores that did not implement the incentive plan,

STOREQTR = Number of quarters of service at the store by an employee prior to termination of the plan,

PLANQTR = Number of quarters of service by an employee under the incentive plan, (for EXISTSTAY and EXISTQUIT employees this takes on a value of 1 or 2 during the two quarters prior to termination, and 0 for the remaining quarters. For JOINSTAY and JOINQUIT employees, this variable is 0 in all quarters), $\mathrm{D}_{\mathrm{i}}^{\mathrm{JQ}}, \mathrm{D}_{\mathrm{i}}^{\mathrm{JS}}$, and $\mathrm{D}_{\mathrm{i}}^{\mathrm{EQ}}$ denote JOINQUIT, JOINSTAY, and EXISTQUIT employees, respectively, $\varepsilon_{\text {it }}$ is the error term.

We use the random effects model for estimation purposes because a component of overall error is randomly distributed across individuals ${ }^{4}$ (Greene, 1993, pp. 469-475). The fixed effects model is not feasible given the above specification. More importantly, the individual effects for different employees are best; modeled as varying around the average due to unidentifiable stochastic factors (see Mundlak 1978).

The termination of the incentive plan resulted in a decline in storewide sales. Is this decline due to effort or selection effects, or both? We examine effort effects by investigating the change in an individual worker's sales productivity over time, as measured by the $\delta$ coefficients. Observe that because TERMQTR is measured as the number of quarters of experience after the termination of the plan, $\delta$ represents average productivity improvement per quarter of post-termination experience. A positive (negative) $\delta$ coefficient indicates a productivity improvement (decline)

\footnotetext{
${ }^{4} \mathrm{We}$ also examine all of the coefficients and hypotheses tests presented in this paper using OLS estimates of the above equation and find the results to be robust. However, the OLS estimates are inefficient as the Breusch-Pagan (1980) test rejects the null hypothesis that the individual effects are zero.
} 
over time after termination of the plan. However, even a positive $\delta$ less than $\mu$ indicates a relative decrease in productivity after termination compared to the pre-termination period.

Selection effects are examined by comparing the initial productivity of the different types of workers as measured the $\lambda$ coefficients. Overall productivity differences are estimated using contrasts. For instance, ascertaining whether the productivity of JOINSTAY employees at the end of the fourth quarter after termination is greater than that of EXISTQUIT employees at the same point in time requires the test of the following inequality: $\lambda^{\mathrm{JS}}+4 \delta^{\mathrm{JS}}>\lambda^{\mathrm{EQ}}+4 \delta^{\mathrm{EQ}}$ without taking into account prior store experience of EXISTQUIT employees.

Table 5 presents the regression results relating employee type, plan and termination experience, and store experience to sales per hour in constant dollars. The estimated $\lambda$ coefficients in the third column of panel A of table 5 suggest that the EXISTSTAY employees $\left(\lambda^{\mathrm{ES}}=1.66^{5}\right)$ had the highest productivity and the JOINSTAY employees have the lowest productivity $\left(\lambda^{\mathrm{JS}}=-15.48\right.$ ) just after termination. We present tests comparing the productivity of various employee types in panel B of table 5 . Tests 1.1 and 1.2 compare the productivities of EXISTSTAY and EXISTQUIT employees at the beginning of the first and eighth quarter after termination. These tests indicate that the productivity of EXISTSTAY employees is similar to that of EXISTQUIT employees, suggesting that the existing employees who quit after the plan's termination are as productive as those that stay. Furthermore, other tests shown in panel B reveal that the employees who join after the plan's termination and stay with the store, i.e. JOINSTAY, have considerably less productivity than existing employees, thus, documenting a selection-effect that adversely impacts overall sales.

5 Observe that in our estimation model the average level of sales per hour for the existing employees prior to termination of the plan is captured in the intercept, and $\delta$ represents the increase in sales per hour per quarter for the two quarters prior to termination. Thus, the value of $\lambda^{\mathrm{ES}}(=1.66)$ is mainly due to the productivity gain in the two PLANQTR periods $(2 * 0.78)$. 
We evaluate the effect of termination of explicit incentives on sequential changes in employee hourly productivity by examining the $\delta$ coefficients in panel A of table 5. They reveal that only the employees who join after the plan's termination and remain through the sample period, the JOINSTAY employees, improve sales productivity each period under the plan $\left(\delta^{\mathrm{SS}}=0.64\right)$. The coefficient $(\mu)$ of PLANQTR in panel $\mathrm{A}$ is positive suggesting that the productivity gains of existing employees before termination of the plan was positive, but their $\delta$ coefficients suggest that the gains for these employees after termination are insignificant. Consistent with this observation, tests 3.1 and 3.2 in panel B indicate that although there is no absolute decrease in sales gains after termination for existing employees, there is evidence of attenuating effect of eliminating incentives on subsequent period productivity increases.

To ensure that cross-sectional differences across stores are not the main reason for our results, we also estimate the average coefficients based on the 15 individual store-level regressions. Results shown in the far right column of panel A are consistent with those based on the pooled regression. In addition, an analysis of individual store regressions suggests that JOINSTAYs have (significantly) lower productivity in (11) 11 out of the 15 regressions and JOINQUITs have (significantly) lower productivity in (nine) 11 out of the 15 regressions when compared to that of EXISTQUITs. Overall, our results are robust across pooled and individual store regressions. They indicate that most of the change in hourly sales productivity resulted from a specific selection effect, namely the inability of the firm to hire workers after the plan's termination that were as productive as the workforce that existed at the time of the plan's termination. Specifically, over time, workers who leave are being replaced by less productive individuals. We do not find that the plan's termination results in a change in effort for those who came off the plan.

Regression test results alone are not informative about the relative magnitudes of the selection and effort effects on a store's average hourly sales productivity. Determining their magnitudes requires the consideration of the relative mix of employee types for each quarter as well as each type's initial productivity and subsequent productivity gains (or declines). Therefore, we first compute the average 
store's employee mix for each quarter. Using this empirical distribution of employee types, we compute the average hourly sales productivity by weighting the employee-type productivity estimates (derived from the coefficient estimates in table 5) by the proportion of different employee types. Specifically, we denote the overall productivity in quarter $\mathrm{t}$ as $\mathrm{p}_{\mathrm{t}}=\sum_{\mathrm{i}}^{\sum_{\mathrm{w}}} \mathrm{p}_{\mathrm{it}}$, where

$$
\begin{aligned}
& \mathrm{w}_{\mathrm{it}}=\text { proportion of workforce of employee type } \mathrm{i} \text { in period } \mathrm{t}, \\
& \mathrm{i}=\text { EXISTSTAY, JOINSTAY, EXISTQUIT, and JOINQUIT, } \\
& \mathrm{p}_{\mathrm{it}}=\text { sales per hour of employee type } \mathrm{i} \text { in period } \mathrm{t} .
\end{aligned}
$$

The change in store productivity from period 0 to period $t$ is:

$$
\mathrm{p}_{\mathrm{t}}-\mathrm{p}_{0}=\sum_{\mathrm{i}} \mathrm{w}_{\mathrm{it}} \mathrm{p}_{\mathrm{it}}-\sum_{\mathrm{i}} \mathrm{w}_{\mathrm{i} 0} \mathrm{p}_{\mathrm{i} 0}=\sum_{\mathrm{i}}\left(\mathrm{w}_{\mathrm{it}}-\mathrm{w}_{\mathrm{i} 0}\right) \mathrm{p}_{\mathrm{i} 0}+\sum_{\mathrm{i}} \mathrm{w}_{\mathrm{it}}\left(\mathrm{p}_{\mathrm{it}}-\mathrm{p}_{\mathrm{i} 0}\right) .
$$

In this expression, the first term is the selection effect and the second term is the effort effect. Figure 2 displays estimated average sales per hour for a representative store over an eight-quarter period beginning two quarters before termination. It is apparent from the figure that the selection effect contributes to the continuing decrease in store sales productivity, whereas the effort effect may be attenuating some of the losses in productivity. The estimated average store level sales losses in the quarter after termination of the incentive plan based on figure 2 and the point-estimates from tables 3 and 4 are similar, further providing evidence of the robustness of our results.

In summary, while our store level results suggest sales decline patterns consistent with effort and selection effects, analysis of individual productivity and workforce changes indicates that the decline in sales is due to one type of sorting. The fact that an individual's productivity did not change after the plan's removal may be explained by the fact that individual productivity continued to be reported to the employee after the plan's termination. This information may have aided in monitoring employee output, as well as providing feedback to employees useful for learning how to sell more effectively. Moreover, because most individual's wages were increased, there was less incentive to shirk and potentially face unemployment. The wage increase also may have helped retain good employees, as we find little 
difference in productivity between the employees who were with the firm during the plan that left versus those that stayed. The plan's termination, however, resulted in the inability of the firm to attract and retain new employees that were as productive as those employees who left subsequent to the plan's termination. Thus, the negative financial impact from the removal of incentives appears to have resulted mainly from sorting effects.

\section{Conclusion}

This paper examines the long-term financial impacts from the termination of a performance-based compensation plan. Upon the plan's termination there is no change in information detailing individual performance, no additional managerial activities, and hourly wages at termination are increased to reflect prior productivity. Therefore, the termination gives us a unique opportunity to investigate incentive impacts.

We find that the termination of the incentive plan is associated with immediate decreases in sales and profits, and that these decreases persist over time. Using individual employee level data we also document that a particular selection effect is mainly responsible for the declining sales. Specifically, the employees who join and remain with the firm after the plan's termination are not as productive as those employees that were with the firm prior to the plan's termination but left after the plan's termination. This result is particularly noteworthy because sparse evidence exists on the selection effects of incentive plans (Lo et al. 2011) and there is little evidence on the efficacy of incentive plans actually used (Kishore et al. 2013). Our findings also suggest that the positive effects of continued monitoring of remaining employees and feedback to them about their performance after the termination of explicit incentives attenuated the losses from selection effects.

As in any event study, there are many factors that may mitigate the validity of our findings. Other events such as economy-wide or local demand factors, changes in labor markets, competition or other changes in the firm's management practices that occurred concurrent with the plan's termination might be responsible for this paper's findings. In addition, our estimates are dependent on our ability to appropriately model the factors that drive sales, expenses and profits. It is important to note that our post- 
termination data spans only two years and it is possible that longer time-series may reveal that the gains attributable to the incentive plan might have vanished after a longer time. Finally, while we document negative impacts from the plan's termination, and ascribe most of these impacts to selection effects, we cannot identify exactly how, if at all, agents' behavior changed once the plan was terminated. 


\section{REFERENCES}

Abowd J (1990). Does performance-based managerial compensation affect corporate performance? Industrial and Labor Relations Review 43(3):52-74.

Baker G (2000). The use of performance measures in incentive contracting. American Economic Review 90(2):415-420.

Balmaceda F (2008). Uncertainty, pay for performance, and asymmetric Information. The Journal of Law, Economics, \& Organization 25(2):400-441.

Banker RD, Lee S, and Potter G (1996). A field study of the impact of a performance-based incentive plan. Journal of Accounting and Economics 21:195-226.

Banker RD, Lee S, Potter G, and Srinivasan D (2000). An empirical analysis of continuing improvements following the implementation of a performance-based compensation plan. Journal of Accounting and Economics 30(3):315-350.

Basu AK, Lal R, Srinivasan V, and Staelin R (1985). Salesforce compensation plans: An agency theoretic perspective. Marketing Science 4(Fall) 267-291.

Beer M and Cannon M (2004). Promise and peril in implementing pay-for-performance. Human Resource Management 43(1): 3-20.

Benabou R and Tirole J (2003). Intrinsic and extrinsic motivation. Review of Economic Studies 70:489520.

Bidwell M, Briscoe F, Fernandez-Mateo I, and Sterling A (2013). The employment relationship and inequality: how and why changes in employment practices are reshaping rewards in organizations. The Academy of Management Annals 7(1):61-121.

Booth AL and Frank J (1999). Earnings, productivity, and performance-related pay. Journal of Labor Economics 17(3):447-463.

Breusch T and Pagan A (1980). The LM test and its applications to model specification in econometrics. Review of Economic Studies 47:239-254. 
Brooks RM, May DO, and Mishra CS (2001). The performance of firms before and after they adopt accounting-based performance plans. Quarterly Review of Economics and Finance 41(2):205-222.

Cadsby CB, Song F, and Tapon F (2007). Sorting and incentive effects of pay for performance: an experimental investigation. Academy of Management Journal 50(2):387-405.

Camerer CF and Hogarth RM (1999). The effects of financial incentives in experiments: a review and capital-labor-production framework. Journal of Risk and Uncertainity 19(1-3):7-42.

Campbell CM (1993). Do firms pay efficiency wages? Evidence with data at the firm level. Journal of Labor Economics 11(3):442-470.

Capelli P and Chauvin K (1991). An interplant test of the efficiency wage hypothesis. Quarterly Journal of Economics 106(3):769-787.

Chi W, Freeman RB, and Kleiner MM (2011). Adoption and termination of employee involvement programs. Review of Labour Economics \& Industrial Relations 25(1):45-62.

Chu K (2004). Employers see lackluster results linking salary to performance. Wall Street Journal (June 15), D2.

Chung DJ, Steenburgh T, and Sudhir K (2013). Do bonuses enhance sales productivity? A dynamic structural analysis of bonus-based compensation plans. Harvard Business School Working Paper No. 1491283:1-48.

Coughlan A and Narasimhan C (1992). An Empirical Analysis of Salesforce Compensation Plans. Journal of Business 65(1): 93-122.

Coughlan A, Misra S and Narasimhan C (2005). Salesforce Compensation: An Analytical and Empirical Examination of the Agency Theoretic Approach. Quantitative Marketing and Economics 3(1): 5-39.

Cyranoski D (2014). Chinese science gets mass transformation. Nature: International weekly journal of science 513 (7519):468-469.

Deci E, Koestner R, and Ryan RM (1999). A meta-analytic review of experiments examining the effects of extrinsic rewards on intrinsic motivation. Psychological Bulletin 125(6):627-668.

Deci E and Ryan RM (1985). Intrinsic motivation and self-determination in human behavior (Plenum Press, New York, NY). 
Drago R and Garvey G (1998). Incentives for helping on the job: Theory and evidence. Journal of Labor Economics 16(1):1-25.

Ewing BT (1996). Wages and performance-based pay: Evidence from the NLSY. Economic Letters 51:241-246.

Feltham G and Xie J (1994). Performance measure congruity and diversity in multi-task principal/agent relations. Accounting Review 69(3):429-453.

Frey BS and Oberholzer-Gee F (1997). The cost of price incentives: an empirical analysis of motivation crowding-out. The American Economic Review 87(4):746-755.

Gneezy U and Rustichini A (2001). Pay enough or don't pay at all. The Quarterly Journal of Economics 115(3):791-810.

Gneezy U, Meier S and Rey-Biel P (2011). When and why incentives (don't) work to modify behavior. Journal of Economic Perspectives 25(4):191-210.

Greene W (1993). Econometric Analysis (Macmillan Publishing Company, New York, NY).

Hauser JR, Simester DI, and Wernerfelt B (1994). Customer satisfaction incentives. Marketing Science13(4):327-350.

Hewitt A (2014). New Aon Hewitt survey shows 2014 variable pay spending spikes to record-high level. Press Release August 27, 2014.

Holmstrom B and Milgrom P (1991). Multitask principal-agent analyses: Incentive contracts, asset ownership, and job design. Journal of Law, Economics, and Organization 7:24-52.

Humphrey T (1990a). Report on your business incentives: Dupont workers left empty handed. The Globe and Mail: B5.

Humphrey T (1990b). Dupont unit scraps pay raise experiment. Chicago Sun-Times 49.

Jaques E, Rice A K, and Hill J M M (1951). The Social and Psychological Impact of a Change in Method of Wage Payment: (The Glacier Project-V). Human Relations 4:315-340.

Jensen M and Murphy KJ (1990). Performance pay and top management incentives. Journal of Political Economy 98(2):225-264. 
John G and Weitz B (1989). Salesforce compensation: An empirical investigation of factors related to the use of salary versus incentive compensation. Journal of Marketing Research 21: 278-289.

Joseph K and Kalwani MU (1995). The impact of environmental uncertainty on the design of salesforce compensation plans. Marketing Letters 6(3):183-197.

Kishore S, Rao RS, Narasimhan O, and John G (2013). Bonuses Versus Commissions: A Field Study. Journal of Marketing Research L:317-333

Kohn A (1993). Punished by Rewards: The Trouble with Gold Stars, Incentive Plans, A's, Praise and Other Bribes (Houghton Mifflin, Boston, MA).

Kreps DM (1997). Intrinsic motivation and extrinsic incentives. The American Economic Review 87(2): 359-364.

Laabs JJ (1997). Newsfile. Workforce: 23-24.

Lal R and Staelin R (1986). Salesforce Compensation Plans in Environments With Asymmetric Information. Marketing Science 5(3): 179-198.

Latham GP and Dossett DL (1978). Designing incentive plans for union employees: A comparison of continuous and variable reinforcement schedules. Personnel Psychology 31:47-61.

Lazear E (1989). Pay equality and industrial politics. Journal of Political Economy 97:561-580.

Lazear EP (2000). Performance, pay and productivity. The American Economic Review 90(5):1346-1361. Lepper M, Greene D, and Nisbett R (1973). Undermining children's intrinsic interest with extrinsic reward. Journal of Personality and Social Psychology 28:129-137.

Libby R and Lipe MG (1992). Incentives, effort and the cognitive processes involved in accountingrelated judgments. Journal of Accounting Research 30:249-273.

Lo D, Ghosh M, and LaFontaine F (2011). The incentive and selection roles of sales force compensation contracts. Journal of Marketing Research XLVIII:781-798.

Mantrala MK, Gopalakrishna S, Albers S, Joseph K, Krafft M, Nasarimhan C, Caldieraro F, Jensen O, Lal R, Zoltners A and Lodish L (2010). Sales Force Modeling. Marketing Letters 21(3): 255-272. 
Milgrom P and Roberts J (1992). Economics, Organization, and Management (Prentice Hall, Englewood Cliffs, NJ).

Misra S and Nair HS (2011). A Structural Model of Sales-Force Compensation Dynamics: Estimation and Field Implementation. Quantitative Marketing and Economics 9(3): 211-257.

Morgan A and Poulsen A (2001). Linking pay to performance-compensation proposals in the S\&P 500.

Journal of Financial Economics 62(3):489-523.

Mundlak Y (1978). On the pooling of time-series and cross sectional data. Econometrics 46:69-86.

Murphy K (1986). Incentives, learning and compensation: A theoretical and empirical investigation of managerial labor contracts. The Rand Journal of Economics 17:59-76.

Oettinger GS (2001). Do piece rates influence effort choices? Evidence from stadium vendors. Economics Letters 73: 117-123.

Paarsch HJ and Shearer B (2000). Piece rates, fixed wages, and incentive effects: Statistical evidence from payroll records. International Economic Review 41(1):59-91.

Park RE and Mitchell BM (1980). Estimating the autocorrelated error model with trended data. Journal of Econometrics 13:185-201.

Pfeffer J (1998). Six dangerous myths about pay. Harvard Business Review 7(3):109-119.

Prais SJ and Winsten CB (1954). Trend estimators and serial correlation, Cowels Commission Discussion Paper 383, Chicgo, IL.

Prendergast C (1999). The provision of incentives in firms. Journal of Economic Literature XXXVII:763.

Rao RC (1990). Compensating heterogeneous salesforces: some explicit solutions. Marketing Science 9:319-341.

Rigby D (2001). Management tools and techniques: A survey. California Management Review 43(2):139160. 
Rothe HF (1970). Output rates among welders: Productivity and consistency following removal of a financial incentive system. Journal of Applied Psychology 54(6):549-551.

Rynes SL, Gerhart B, and L Parks (2005). Personnel psychology: performance evaluation and pay for performance. Annual Review of Psychology 56: 571-600.

Salop S (1979). A model of the natural rate of unemployment. American Economic Review 69:117-125.

Schwadel F (1990). Chain finds incentives on Hard Sell. Wall Street Journal (July 5), B1.

Shapiro C and Stiglitz JE (1984). Equilibrium unemployment as a worker discipline device. American Economic Review LXXIV:433-444.

Sprinkle G (2000). The effects of incentive contracts on learning and performance. The Accounting Review 75(3):299-326.

Stewart J (1999). Adverse selection and pay compression. Southern Economic Journal 65(4):885-899.

Tanikawa M (2001). Fujitsu decides to backtrack on performance-based pay. New York Times (March 22), W1.

Torsoli A and Staley O (2014). GlaxoSmithKline said to plan reorganization, U.S. cuts. Bloomberg News. http://bloom.bg/11CW2C9.

Wagner JA, Rubin PA, and Callahan TJ (1988). Incentive payment and non-managerial productivity: An interrupted time series analysis of magnitude and trend. Organizational Behavior and Human Decision Processes 42:47-74.

Yellen JL (1984). Efficiency wage models of unemployment. American Economic Review LXXIV:200205. 


\section{Table 1}

\section{Average Size of Retail Outlets by Incentive Plan Presence Immediately Prior to Termination (means, with medians in parentheses below)}

\begin{tabular}{lccc}
\hline & $\begin{array}{c}\text { Stores } \\
\text { with plan }\end{array}$ & $\begin{array}{c}\text { Stores } \\
\text { without plan }\end{array}$ & $\begin{array}{c}\text { Statistical tests of } \\
\text { difference }\end{array}$ \\
\hline SQFEET (000's) & 227.52 & 220.42 & $p(t)=0.88$ \\
& $(187)$ & $(187)$ & $p(z)=0.99$ \\
SALES (millions) & $\$ 52.66$ & $\$ 37.81$ & $p(t)=0.13$ \\
& $(\$ 42.03)$ & $(\$ 28.79)$ & $p(z)=0.39$ \\
SALESSQFT & $\$ 239.92$ & $\$ 187.81$ & $p(t)=0.03$ \\
& $(\$ 242.97)$ & $(\$ 187.88)$ & $p(z)=0.09$ \\
PROFITSQFT & $\$ 63.73$ & $\$ 52.69$ & $p(t)=0.11$ \\
& $(\$ 59.27)$ & $(\$ 47.63)$ & $p(z)=0.30$ \\
Number of stores & 15 & 19 & \\
\hline
\end{tabular}

The mean values reported in the table are disguised by multiplying by a scalar. The statistical tests are not affected by this transformation.

Stores that have the performance-based plan immediately prior to its termination are classified as 'stores with plan'.

$p(t) \quad=$ probability that the means of the two groups are equal.

$p(z) \quad=$ probability that the medians of the two groups are equal.

SQFEET = square footage of store.

SALES = annual sales of store.

SALESSQFT = annual sales per square foot of store space.

$P R O F I T S Q F T=$ annual profit per square foot of store space. 
Table 2

\section{Mean Financial Ratios for Retail Outlets by Incentive Plan Presence Immediately Prior to Termination of the Incentive Plan} (medians in parentheses)

\begin{tabular}{cccc}
\hline Financial ratios & $\begin{array}{c}\text { Stores } \\
\text { with plan }\end{array}$ & $\begin{array}{c}\text { Stores } \\
\text { without plan }\end{array}$ & $\begin{array}{c}\text { Statistical tests of } \\
\text { difference }\end{array}$ \\
\hline COS & .618 & .614 & $p(t)=.47$ \\
SALES & $(.61)$ & $(.61)$ & $\mathrm{p}(\mathrm{z})=.31$ \\
SUPPORT & .028 & .034 & $p(t)=.01$ \\
SALES & $(.03)$ & $(.03)$ & $\mathrm{p}(\mathrm{z})=.02$ \\
SELL & .093 & .081 & $p(t)=.01$ \\
SALES & $(.09)$ & $(.08)$ & $\mathrm{p}(\mathrm{z})=.02$ \\
$\frac{\text { PROFIT }}{\text { SALES }}$ & .259 & .269 & $p(t)=.30$ \\
$\mathrm{~N}$ & $(.26)$ & $(.28)$ & $\mathrm{p}(\mathrm{z})=.31$ \\
\hline
\end{tabular}

Mean values reported in the table are disguised by multiplying by a scalar. The statistical tests are not affected by this transformation.

Stores that have the performance-based plan immediately prior to its termination are classified as 'stores with plan'.

$p(t) \quad=$ probability that the means of the two groups are equal.

$p(z) \quad=$ probability that the medians of the two groups are equal.

COS $\quad=$ cost of merchandise sold.

SUPPORT = include indirect labor costs for stocking, cleaning, wrapping, and monitoring merchandise.

SELL = wages and salaries of sales consultants and their immediate managers.

PROFIT = operating profit, SALES less expenses identified above. 


\section{TABLE 3}

\section{Parameter Estimates Relating to Adoption and Termination of Incentive Plan} (t statistics in parentheses)

$$
\begin{aligned}
& Y_{s t}=\sum_{s=1}^{15}\left(\alpha_{s} \mathrm{D}_{s}+\beta_{s} \mathrm{D}_{s} \mathrm{AVGY}_{t}\right)+\sum_{q=2}^{4} \eta_{q} D_{q}+\gamma \mathrm{RGINC}_{\mathrm{st}} \\
& +\lambda_{1} \mathrm{D}_{s t}^{P}+\lambda_{2} \mathrm{PLANEXP}_{s t}+\lambda_{3} \mathrm{D}_{\mathrm{st}}^{\mathrm{T}}+\lambda_{4} \mathrm{TERMEXP}_{s t}+e_{s t}
\end{aligned}
$$

\begin{tabular}{|c|c|c|c|}
\hline Variable & $\begin{array}{l}\text { Co } \\
\text { eff. }\end{array}$ & SALES & PROFIT \\
\hline $\mathrm{D}_{s t}^{P}$ & $\lambda_{1}$ & $\begin{array}{c}685.18 \\
(3.16)\end{array}$ & $\begin{array}{c}-185.71 \\
(-2.14)\end{array}$ \\
\hline $\mathrm{PLANEXP}_{s t}$ & $\lambda_{2}$ & $\begin{array}{l}88.96 \\
(9.65)\end{array}$ & $\begin{array}{l}25.66 \\
(6.80)\end{array}$ \\
\hline $\mathrm{D}_{s t}^{T}$ & $\lambda_{3}$ & $\begin{array}{c}-990.13 \\
(-2.80)\end{array}$ & $\begin{array}{r}-204.03 \\
(-1.55)\end{array}$ \\
\hline $\mathrm{TERMEXP}_{s t}$ & $\lambda_{4}$ & $\begin{array}{c}-120.61 \\
(-5.39)\end{array}$ & $\begin{array}{l}-30.72 \\
(-3.61)\end{array}$ \\
\hline Adj. $\mathrm{R}^{2}$ & & $98 \%$ & $95 \%$ \\
\hline $\mathrm{p}\left(\lambda_{2}+\lambda_{4}=0\right)$ & & 0.13 & 0.51 \\
\hline $\mathrm{p}\left(\left(\lambda_{1}+34 * \lambda_{2}+\lambda_{3}=0\right)\right.$ & & 0.01 & 0.01 \\
\hline $\mathrm{p}\left(\left(\lambda_{1}+46^{*} \lambda_{2}+\lambda_{3}+12^{*} \lambda_{4}=0\right)\right.$ & & 0.01 & 0.01 \\
\hline $\mathrm{p}\left(\left(\lambda_{1}+58 * \lambda_{2}+\lambda_{3}+24 * \lambda_{4}=0\right)\right.$ & & 0.01 & 0.01 \\
\hline $\mathrm{N}$ & & 1485 & 1305 \\
\hline
\end{tabular}

RGINC $_{s t} \quad=$ relative growth in personal income of county of store location.

$\mathrm{D}_{s} \quad=1$ if store $\mathrm{s}$, otherwise zero.

$\mathrm{D}_{s t}^{P} \quad=1$ once store has been on the incentive plan, otherwise zero.

PLANEXP $_{s t}=$ Number of months since incentive plan implementation.

$\mathrm{D}_{s t}^{T} \quad=1$ in periods of termination of the plan, otherwise zero.

TERMEXP $_{s t}=$ Number of months since termination of plan. 


\section{TABLE 4}

\section{Parameter Estimates Relating to Adoption and Termination of Incentive Plan}

(t statistics in parentheses)

$$
Y_{s t} \text { AVGY }_{t}=\sum_{s=1}^{15} \alpha_{s} \mathrm{D}_{s}+\sum_{q=2}^{4} \eta_{q} D_{q}+\gamma \mathrm{RGINC}_{\mathrm{st}}+\lambda_{1} \mathrm{D}_{s t}^{P}+\lambda_{2} \mathrm{PLANEXP}_{s t}+\lambda_{3} \mathrm{D}_{\mathrm{st}}^{\mathrm{T}}+\lambda_{4} \mathrm{TERMEXP}_{s t}+
$$

\begin{tabular}{|c|c|c|c|}
\hline Variable & Coeff. & SALES & PROFIT \\
\hline $\mathrm{D}_{s t}^{P}$ & $\lambda_{1}$ & 0.071 & -0.107 \\
& & $(4.17)$ & $(-1.48)$ \\
PLANEXP $_{s t}$ & $\lambda_{2}$ & 0.005 & 0.009 \\
& & $(5.73)$ & $(3.03)$ \\
$\mathrm{D}_{s t}^{T}$ & $\lambda_{3}$ & -0.053 & -0.137 \\
& & $(-1.96)$ & $(-1.22)$ \\
$\mathrm{TERMEXP}_{s t}$ & $\lambda_{4}$ & -0.007 & -0.013 \\
& & $(-4.39)$ & $(-1.82)$ \\
\hline $\mathrm{Adj} . \mathrm{R}^{2}$ & & $89 \%$ & $28 \%$ \\
\hline $\mathrm{p}\left(\lambda_{2}+\lambda_{4}=0\right)$ & & & \\
\hline $\mathrm{p}\left(\left(\lambda_{1}+34 * \lambda_{2}+\lambda_{3}=0\right)\right.$ & & 0.04 & 0.57 \\
\hline $\mathrm{p}\left(\left(\lambda_{1}+46^{*} \lambda_{2}+\lambda_{3}+12 * \lambda_{4}=0\right)\right.$ & & 0.01 & 0.43 \\
\hline $\mathrm{p}\left(\left(\lambda_{1}+58^{*} \lambda_{2}+\lambda_{3}+24 * \lambda_{4}=0\right)\right.$ & & 0.03 & 0.61 \\
\hline & & & \\
\hline $\mathrm{N}$ & & 1485 & 1305 \\
\hline
\end{tabular}

RGINC $_{s t} \quad=$ relative growth in personal income of county of store location.

$\mathrm{D}_{s} \quad=1$ if store $\mathrm{s}$, otherwise zero.

$\mathrm{D}_{s t}^{P} \quad=1$ once store has been on the incentive plan, otherwise zero.

PLANEXP $_{s t}=$ Number of months since incentive plan implementation.

$\mathrm{D}_{s t}^{T} \quad=1$ in periods of termination of the plan, otherwise zero.

TERMEXP $_{s t}=$ Number of months since termination of plan. 
Table 5

Regression Results for Employee Sales Productivity ( $\mathrm{t}$-values in parentheses, $\mathrm{n}=37,623$ employee-quarters)

$$
\begin{aligned}
& H_{S A L E S} i t=\alpha+\sum_{s=2}^{15} \beta_{S} D_{s}+\sum_{w=2}^{14} r_{w} D_{w}+\sum_{q=2}^{4} p_{q} D_{q}+\gamma \text { CNTRLSPH }_{t}+\mu \text { PANQTR }_{i t}+\eta \text { STOREQTR }_{i} \\
& +\lambda^{E S} D^{E S}+\lambda^{E Q} D^{E Q}+\lambda^{J S} D^{J S}+\lambda^{J Q} D^{J Q}+\delta^{E S} D^{E S} T_{E R M Q T R_{i t}}+\delta^{E Q} D^{E Q_{T E R M Q T R}}{ }_{i t} \\
& +\delta^{J S} D^{J S} T_{T E R M Q T R}+\delta^{J Q_{D}} Q_{T_{\text {TERMQTR }}}+\varepsilon_{i t}
\end{aligned}
$$

\begin{tabular}{|c|c|c|c|}
\hline Variable & Coefficient & \begin{tabular}{|c} 
Estimates \\
(based on pooled \\
data from 15 stores) \\
\end{tabular} & $\begin{array}{c}\text { Avg. Estimates } \\
\text { (based on individual } \\
\text { regressions of } 15 \text { stores) }\end{array}$ \\
\hline $\mathrm{D}^{\mathrm{ES}}$ & $\lambda^{\mathrm{ES}}$ & $\begin{array}{c}1.66^{*} \\
(1.88)\end{array}$ & $\begin{array}{c}1.10 \\
(1.18)\end{array}$ \\
\hline $\mathrm{D}^{\mathrm{EQ}}$ & $\lambda^{\mathrm{EQ}}$ & $\begin{array}{c}-0.11 \\
(-0.09)\end{array}$ & $\begin{array}{l}-0.05 \\
(-1.20)\end{array}$ \\
\hline $\mathrm{D}^{\mathrm{JS}}$ & $\lambda^{\mathrm{JS}}$ & $\begin{array}{l}-15.48 * * * \\
(-11.90)\end{array}$ & $\begin{array}{l}-14.45^{* * *} \\
(-2.86)\end{array}$ \\
\hline $\mathrm{D}^{\mathrm{JQ}}$ & $\lambda^{\mathrm{JQ}}$ & $\begin{array}{l}-3.35^{* * *} \\
(-2.15)\end{array}$ & $\begin{array}{l}-5.10 * * \\
(-1.82)\end{array}$ \\
\hline $\mathrm{D}^{\mathrm{ES}} \mathrm{TERMQTR}$ & $\delta^{\mathrm{ES}}$ & $\begin{array}{c}0.04 \\
(0.29)\end{array}$ & $\begin{array}{c}-0.58 \\
(-0.70)\end{array}$ \\
\hline $\mathrm{D}^{\mathrm{EQ}}$ TERMQTR & $\delta^{\mathrm{EQ}}$ & $\begin{array}{c}0.17 \\
(0.54)\end{array}$ & $\begin{array}{c}-0.71 \\
(-1.08)\end{array}$ \\
\hline $\mathrm{D}^{\mathrm{JS}}$ TERMQTR & $\delta^{\mathrm{JS}}$ & $\begin{array}{l}0.64 * * * \\
(3.37)\end{array}$ & $\begin{array}{c}-0.09 \\
(-0.21)\end{array}$ \\
\hline $\mathrm{D}^{\mathrm{JQ}}$ TERMQTR & $\delta^{\mathrm{JQ}}$ & $\begin{array}{c}0.12 \\
(0.37)\end{array}$ & $\begin{array}{l}-1.21 * * \\
(-2.28)\end{array}$ \\
\hline CNTRLSPH & $\gamma$ & $\begin{array}{c}0.02 \\
(0.12)\end{array}$ & $\begin{array}{c}-0.01 \\
(-0.29)\end{array}$ \\
\hline PLANQTR & $\mu$ & $\begin{array}{l}0.78 * * * \\
(4.50)\end{array}$ & $\begin{array}{l}0.67 * * \\
(1.62)\end{array}$ \\
\hline STOREQTR & $\eta$ & $\begin{array}{l}0.10^{* * *} \\
(5.43)\end{array}$ & $\begin{array}{l}0.07 * * \\
(1.86)\end{array}$ \\
\hline \multicolumn{2}{|l|}{$\mathrm{p}($ model $)$} & 0.01 & 0.01 \\
\hline \multicolumn{2}{|l|}{ Adjusted $\mathrm{R}^{2}$} & 0.45 & 0.19 \\
\hline
\end{tabular}

Panel A: Parameter Estimates 
Table 5 (...continued)

Panel B: Tests

\begin{tabular}{|c|c|c|}
\hline & $\begin{array}{c}\text { Pooled } \\
\text { model }\end{array}$ & $\begin{array}{c}\text { Store-level } \\
\text { Model }\end{array}$ \\
\hline \multicolumn{3}{|c|}{$\begin{array}{l}\text { Productivity of EXISTSTAY versus others } \\
\text { after } 0 \text { or } 8 \text { quarters }\end{array}$} \\
\hline $1.1 \mathrm{p}\left(\lambda^{\mathrm{ES}}=\lambda^{\mathrm{EQ}}\right)$ & 0.16 & 0.62 \\
\hline $1.2 \mathrm{p}\left(\lambda^{\mathrm{ES}}+8 \delta^{\mathrm{ES}}=\lambda^{\mathrm{EQ}}+8 \delta^{\mathrm{EQ}}\right)$ & 0.36 & 0.62 \\
\hline $1.3 p\left(\lambda^{\mathrm{ES}}=\lambda^{\mathrm{JS}}\right)$ & 0.01 & 0.01 \\
\hline $1.4 \mathrm{p}\left(\lambda^{\mathrm{ES}}+8 \delta^{\mathrm{ES}}=\lambda^{\mathrm{JS}}+8 \delta^{\mathrm{JS}}\right)$ & 0.01 & 0.01 \\
\hline \multicolumn{3}{|c|}{$\begin{array}{l}\text { Productivity of JOINSTAY versus others } \\
\text { after } 0 \text { or } 8 \text { quarters }\end{array}$} \\
\hline $2.1 \quad \mathrm{p}\left(\lambda^{\mathrm{JS}}=\lambda^{\mathrm{EQ}}\right)$ & 0.01 & 0.01 \\
\hline $2.2 \mathrm{p}\left(\lambda^{\mathrm{JS}}+8 \delta^{\mathrm{JS}}=\lambda^{\mathrm{EQ}}+8 \delta^{\mathrm{EQ}}\right)$ & 0.01 & 0.04 \\
\hline $2.3 \quad \mathrm{p}\left(\lambda^{\mathrm{JS}}=\lambda^{\mathrm{JQ}}\right)$ & 0.01 & 0.03 \\
\hline $2.4 \mathrm{p}\left(\lambda^{\mathrm{JS}}+8 \delta^{\mathrm{JS}}=\lambda^{\mathrm{JQ}}+8 \delta^{\mathrm{JQ}}\right)$ & 0.01 & 0.74 \\
\hline \multicolumn{3}{|c|}{$\begin{array}{c}\text { Productivity growth rates before and after plan } \\
\text { termination }\end{array}$} \\
\hline $3.1 \mathrm{p}\left(\mu=\delta^{\mathrm{ES}}\right)$ & 0.02 & 0.01 \\
\hline $3.2 \mathrm{p}\left(\mu=\delta^{\mathrm{EQ}}\right)$ & 0.03 & 0.01 \\
\hline
\end{tabular}

TERMQTR $=$ Number of quarters of service by an employee after termination of the plan, CNTRLSPH $=$ Average quarterly sales per hour for the 19 control stores that did not implement the incentive plan,

STOREQTR = Number of quarters of service at the store by an employee prior to termination of the plan, PLANQTR = Number of quarters of service by an employee under the incentive plan, (for EXISTSTAY and EXISTQUIT employees this takes on a value of 1 or 2 during the two quarters prior to termination, and 0 for the remaining quarters. For JOINSTAY and JOINQUIT employees, this variable is 0 in all quarters).

The superscripts ES, EQ, JS, and JQ refer to existing employees who stay with the store until the end of sample period, existing employees who quit before the end of sample period, new employees who join after the termination of the plan and stay with the store until the end of sample period, and new employees who join after the termination of the plan and who quit before the end of sample period, respectively. 


\section{Figure 1}

Plot of average incremental sales relative to control stores around the date of termination of incentive plan

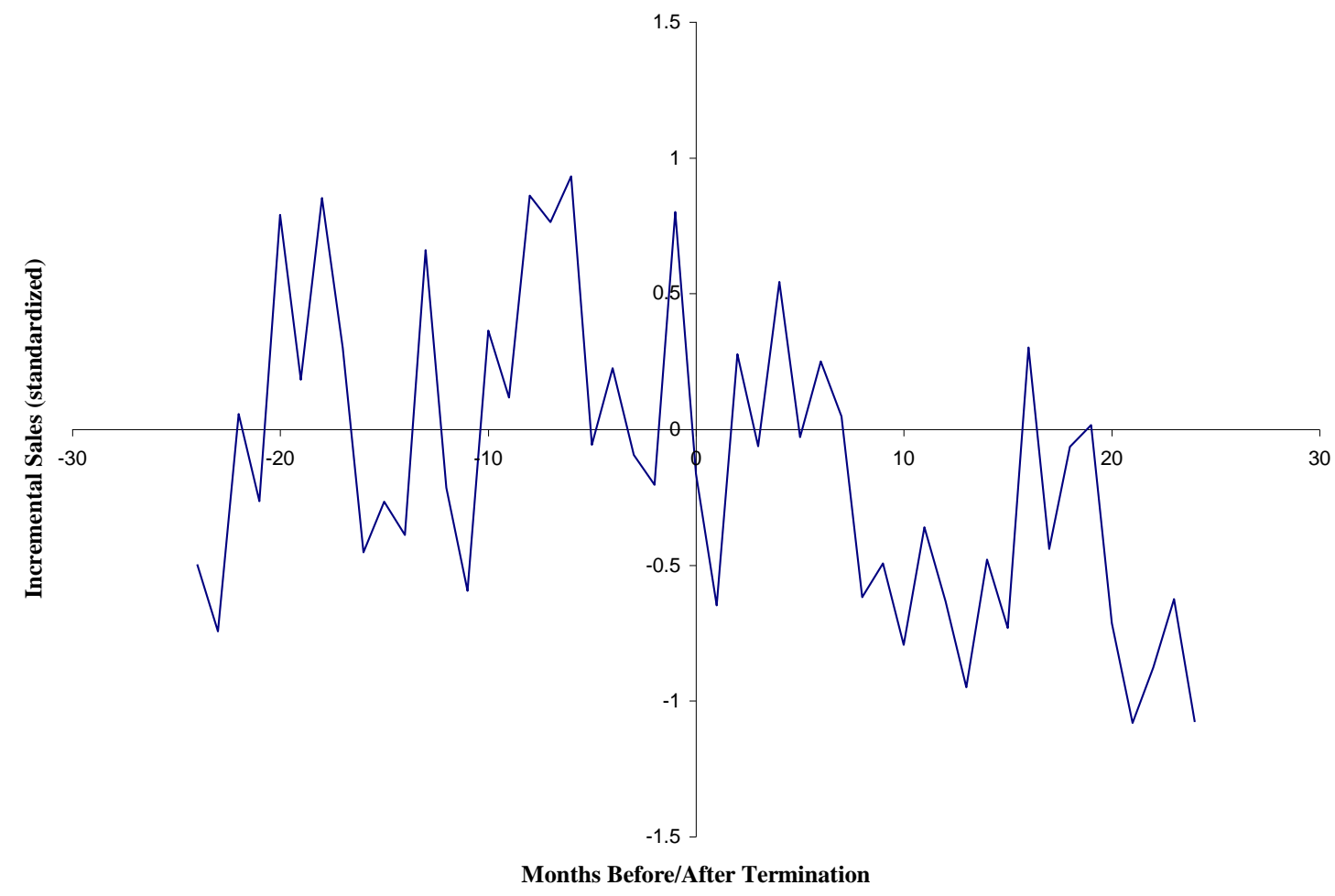

Model: SALES $_{s t}=\alpha_{s}+\beta_{s}$ AVGSAL $_{t}+\varepsilon_{s t}$ for each $s=1, \ldots 15$, where

SALES $_{\mathrm{st}}=$ Sales of store $\mathrm{s}$ in month $\mathrm{t}$,

AVGSAL $_{t}=$ Average monthly sales of the 19 company stores in the same geographic region that did not implement the incentive plan, and

$\hat{\alpha}_{\mathrm{S}}$ and $\hat{\beta}_{\mathrm{S}}$ are estimated using monthly data prior to the plan termination.

Incremental Sales $_{\mathrm{st}}($ standardized $)=1 / 15^{*} \sum_{\mathrm{s}=1}^{15}\left(\operatorname{SALES}_{\mathrm{st}}-\hat{\alpha}_{\mathrm{s}}-\hat{\beta}_{\mathrm{s}} \operatorname{AVGSAL}_{\mathrm{t}}\right) / \sqrt{\operatorname{Var}\left(\varepsilon_{\mathrm{st}}\right)}$

For $\mathrm{t}=-24, \ldots-1,0, \ldots 24$, where $\mathrm{t}=0$ is the month of plan termination. 
Figure 2

Storewide Average Sales Productivity around Termination of the Incentive Plan



